\title{
On the dominance of whole-word knowledge in reading aloud
}

\author{
TROY A. W. VISSER \\ University of British Columbia, Vancouver, British Columbia, Canada \\ and \\ DEREK BESNER \\ University of Waterloo, Waterloo, Ontario, Canada
}

\begin{abstract}
The localist dual-route model of visual word recognition assumes a routine that addresses the pronunciation of all words known to the reader (the lexical-semantic pathway) and another routine, operating in parallel, that assembles pronunciations on the basis of sublexical spelling-sound correspondences. The present experiment exploits the exception effect (in which words that are atypical in terms of their spelling-sound correspondences are named more slowly than typical ones) because it is considered a marker of the joint operation of these two routines. Participants named high- and lowfrequency regular and exception words that were repeated across two blocks of trials. The widely reported interaction between regularity and word frequency is present in Block 1 but is reduced in magnitude in Block 2. DRC, an implemented dual-route model, simulates the data. Taken in conjunction with other reports, the results provide further evidence for a double dissociation between addressed and assembled routines and are consistent with the view that skill in recognizing printed words known to the reader reflects the dominance of orthographic over phonological processing.
\end{abstract}

How do skilled readers recognize printed words? This simple question has exercised cognitive psychologists, neuropsychologists, and neuroscientists since Huey's writings on the topic (e.g., Baluch \& Besner, 1991; Besner, 1999; Coltheart, Curtis, Atkins, \& Haller, 1993; Coltheart, Patterson, \& Marshall, 1980; Coltheart, Rastle, Perry, Langdon, \& Ziegler, 2001; Forster \& Chambers, 1973; Frederiksen \& Kroll, 1976; Frost, 1998; Grainger \& Jacobs, 1996; Hung \& Tzeng, 1981; McClelland \& Rumelhart, 1981; Paap \& Noel, 1991; Patterson, Marshall, \& Coltheart, 1985; Plaut, McClelland, Seidenberg, \& Patterson, 1996; Pugh et al., 1996; Van Orden, Pennington, \& Stone, 1990). Some investigators have started with an idea and looked for supporting evidence; others have started with a phenomenon and attempted to explain it. The present paper starts with the fact that some words are harder to recognize than others and exploits this fact in service of the idea that it can be used to understand some of the mental processes that underlie skilled word recognition.

\section{A PHENOMENON}

English is difficult to learn to read, in large part because its spelling-sound correspondences are often in-

This work was supported by Grant A0998 from the Natural Sciences and Engineering Research Council of Canada to D.B. We thank Max Coltheart for comments on the manuscript and simulation data from DRC, and Ken Foster for editorial assistance. Correspondence concerning this article should be addressed to D. Besner, Psychology Department, University of Waterloo, ON N2L 3G1, Canada (e-mail: dbesner@watarts.uwaterloo.ca). consistent. Indeed, this problem is so pervasive that its effects are evident many years later in skilled readers, in the form of slowed naming times to words that are exceptions to the typical pronunciation of a spelling pattern (e.g., the exceptions warn and pint vs. the typical ${ }^{1}$ pronunciation as in barn and darn and mint and hint). This phenomenon has come to be known as the regularity or exception effect, and it is further qualified by word frequency. High-frequency words generally show little effect of exceptional spelling-sound correspondences (but see Jared, 1995). In contrast, low-frequency exception words are typically $25-40 \mathrm{msec}$ slower and more error prone than low-frequency regular words (e.g., Coltheart \& Rastle, 1994; Paap \& Noel, 1991; Rastle \& Coltheart, 1999b; Seidenberg, 1985; Seidenberg, Waters, Barnes, \& Tanenhaus, 1984; Waters \& Seidenberg, 1985).

One framework for explaining this exception effect and its interaction with word frequency is provided by a localist dual-route framework (e.g., Besner, 1999; Coltheart et al., 2001; Paap \& Noel, 1991; Patterson \& Coltheart, 1987; Rastle \& Coltheart, 1999b). The architecture of this framework includes an orthographic word level in which each node represents a word known to the reader. Presentation of a word results in cascaded activation across feature, letter, and word levels, which spreads to (addresses) whole-word nodes in the phonological output lexicon and, from there, the phonemic buffer and overt speech (see Figure 1).

Activation also spreads from the orthographic word nodes to the semantic system and, from there, to the phonological output lexicon. These parts of the architec- 
ture describe the lexical-semantic routes (i.e., pathways $\mathrm{A}$ and $\mathrm{B}-\mathrm{C}$, respectively). The remaining assembled routine translates print into a phonological code via the application of sublexical spelling-sound correspondences (pathway D in Figure 1); the exact nature of these correspondences is a matter of some debate (e.g., see Coltheart \& Rastle, 1994, vs. Treiman, Mullennix, BijeljacBabic, \& Richmond-Welty, 1995; Rastle \& Coltheart, $1999 \mathrm{~b})$. The output of this process activates the phonemic buffer and then speech. These two routines ( $a d$ dressed and assembled) operate concurrently, but they do not always finish at the same time, because different factors selectively affect the two routines. For example, word frequency affects the addressed pathways, but not the assembled pathway (e.g., Baluch \& Besner, 1991; McCann \& Besner, 1987). In contrast, the number of letters in a word affects the assembled pathway, but not the addressed pathway (Rastle \& Coltheart, 1998; Weekes, 1997).

How does this architecture produce the interaction between regularity and word frequency in the context of the naming task? The first point is that the addressed routine produces the correct pronunciation for regular and exception words but the assembled routine assigns the most typical pronunciation to sublexical spelling-sound correspondences. The assembled routine thus regularizes exception words (e.g., the $i$ in pint is pronounced so as to rhyme with mint). Such regularizations are seen most clearly in patients with an acquired dyslexia, where the workings of the preserved assembled routine are more easily observed because of impairments to the addressed routine (e.g., Patterson et al., 1985).

The second point is referred to as the speed-ofprocessing assumption. In intact readers, the addressed routine processes high-frequency exception words quickly enough that there is little opportunity for the assembled routine to produce a regularized output in time to produce conflict. However, for low-frequency exception words, the addressed routine is sufficiently slow that output from the assembled routine has sometimes been computed. Two different outputs are now present. For example, the assembled route produced the pronunciation for pint so that it rhymes with mint, lint, and dint, and the addressed routine produced the correct phonological code for pint, which conflicts. It takes time to resolve this conflict-hence, the exception effect. In summary, the ex-

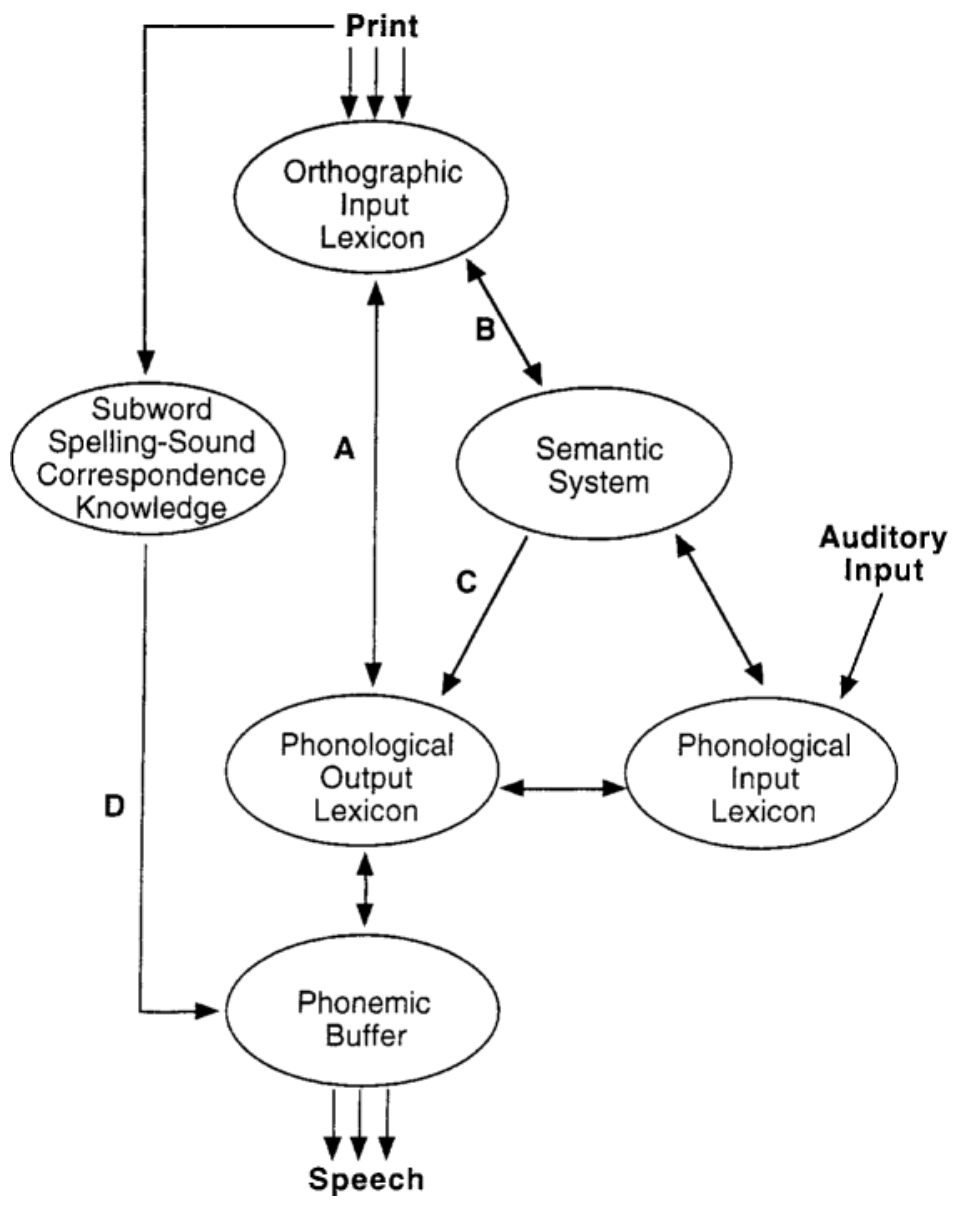

Figure 1. Aspects of a framework for word recognition and naming: a localist dual-route model adapted from Besner (1999). 
ception effect arises because of the nature of the outputs from the different routines and the relative speeds at which these routes operate.

Another qualitative difference between the assembled and the addressed routes is that the former operates serially in a left-to-right manner and the latter processes all the letters in a word in parallel (Coltheart \& Rastle, 1994; Rastle \& Coltheart, 1998, 1999b; Weekes, 1997). It follows that the location of the exceptional segment in an exception word should also affect the magnitude of the exception effect. Outputs from the assembled routine are more likely to conflict with the output from the addressed routine when the exceptional segment is in an early position in the word than when it occurs later on, because of the speed-of-processing assumption. This is precisely what has been observed; Coltheart and Rastle (1994; Rastle \& Coltheart, 1999b) reported that the magnitude of the exception effect decreased linearly as the location of the exceptional segment moved from left to right in the exception word. Moreover, Rastle and Coltheart (1999b) were able to simulate this effect with the dual-route cascaded (DRC) model, whose architecture is as described below.

\section{THE PRESENT EXPERIMENT}

The relative-speed-of-processing logic described above should also apply to the addressed route. The faster the processing in the addressed routine relative to the assembled routine, the smaller the exception effect should be. ${ }^{2}$ This again follows because there is less opportunity for output from the assembled routine to be available in time to compete with output from the addressed routine. The present experiment exploited this logic in the following way. Participants read a set of words aloud that varied on both the regularity dimension and word frequency. They then read all the words again in a second block of trials. It is well known that repetition facilitates naming and that, generally, repetition helps low-frequency words more than it does high-frequency words (e.g., Monsell, 1991; Scarborough, Cortese, \& Scarborough, 1977). We assume that this facilitation occurs because repetition speeds up the operation of the addressed routine, relative to the operation of the assembled routine (see, e.g., Rastle \& Coltheart 1999a). Indeed, we are aware of no evidence from speeded naming experiments with adult readers that demand the interpretation that repetition facilitates the sublexical routine (i.e., a nonword repetition effect could arise through lexical activation of word neighbors).

To the extent that repetition affects the availability of a word's lexical and semantic representations, it should increase the retrieval speed of a low-frequency word via the addressed route, relative to the speed of processing via the assembled route. The magnitude of the exception effect should therefore decrease, as compared with the first time the words were read. In essence, repetition makes low-frequency words behave more like high-frequency words in terms of the time taken to retrieve a pronuncia- tion. Like Coltheart and Rastle (1994; see also Rastle \& Coltheart, 1999b), the present experiment manipulated factors associated with the speed-of-processing assumption. This allowed us to test the assumption explicitly, rather than simply applying it as a post hoc explanation for experimental effects (e.g., as an explanation of why high-frequency words tend not to show an exception effect).

In summary, the relative-speed-of-processing logic, as applied here, predicts a three-way interaction between regularity, word frequency, and repetition in which the magnitude of the regularity $\times$ word frequency interaction will be larger in Block 1 than in Block 2 .

\section{Method}

Participants. Forty students from the cognition subject pool at the University of Waterloo took part in the experiment. All reported normal or corrected-to-normal vision and were native speakers of English.

Stimuli. The items consisted of the 80 words used by Paap and Noel (1991). These words are shown in the Appendix. There were 20 words in each of four categories: high frequency, regular; high frequency, exception; low frequency, regular; and low frequency, exception. Paap and Noel defined target words as regular or exceptions by calculating a consistency score corresponding to the proportion of words with identical endings that rhymed with the target. For example, bury shares an ending, but does not rhyme, with jury and fury. Thus, bury would have a consistency score of $1 / 3$, or .33 . The mean consistency score for exception words was .33 and .26 for low- and high-frequency words, respectively. The mean consistency score for regular words was 1.00 and .97 for low- and high-frequency words, respectively. The median frequencies for the high-frequency words were 393 and 214 for the exception and regular words, respectively; median frequencies for the low-frequency words were 3.5 and 3.5 for the exception and regular words, respectively.

All the stimuli were presented on a CTX color monitor (Model CAC14MG) that was slaved to an IBM-compatible 386DX25 computer running the Micro Experimental Laboratory software. Naming reaction times (RTs, in milliseconds) were obtained via a voiceactivated relay. All the stimuli were presented in lowercase; white characters were presented against a black background. The stimuli were centered horizontally and vertically. Each letter was approximately $4 \mathrm{~mm}$ high $\times 3 \mathrm{~mm}$ wide. The viewing distance was approximately $25 \mathrm{~cm}$.

Procedure. Each trial began with the presentation of a fixation cross in the middle of the screen for $500 \mathrm{msec}$. The fixation cross was then replaced by the presentation of the target word. The participants were asked to read the word aloud as quickly and as accurately as possible. The presentation of the word ended when the voice-activated relay was triggered.

The experimental words were presented twice during the experiment (repetition manipulation), and the participants were not informed of this manipulation, although they were told that there would be two blocks of trials. Following 10 practice trials, the 80 test words were presented in random order. The 80 test words were then presented again in random order. Each participant saw a different random order within a block.

A trial was coded as spoiled if the voice-activated relay was triggered by a noise other than the participant's pronunciation of the presented word (e.g., a cough). Otherwise, a trial was coded as correct or as an error, depending on the accuracy of the participant's pronunciation. The type of pronunciation error made by participants (e.g., regularization) was (unfortunately) not recorded. The participants did not receive any feedback about their performance. The next trial was initiated when the experimenter had finished coding the previous response on the computer. 


\section{Results}

Spoiled trials and trials on which the participants made an error were discarded from the RT analysis. Spoiled trials amounted to $2.5 \%$ of the total trials. Trials on which an error was committed amounted to $4.6 \%$ of the total trials.

RTs from the remaining trials were first screened for outliers in each cell for each participant, using a modified recursive procedure that removes observations on the basis of a floating criterion adjusted for sample size (Van Selst \& Jolicœur, 1994). This resulted in the elimination of $1.8 \%$ of all raw RTs. The remaining RTs were used to calculate a mean for each experimental condition. Mean RTs, their associated standard errors, and percentage of errors are presented in Figure 2.

RT data. A $2 \times 2 \times 2$ analysis of variance (ANOVA) was performed on the data, with word frequency (high vs. low), spelling-sound correspondences (regular vs. exception), and block (first vs. second presentation) as within-subjects factors $\left(F_{1}\right)$ and items, following Paap and Noel (1991), as a between-subjects factor $\left(F_{2}\right)$. All the main effects were significant. High-frequency words were named faster than low-frequency words $\left[F_{1}(1,39)=\right.$
$27.3, M S_{\mathrm{e}}=2,085, p<.001 ; F_{2}(1,76)=22.8, M S_{\mathrm{e}}=$ $1,421, p<.001]$. Regular words were named faster than exception words $\left[F_{1}(1,39)=76.6, M S_{\mathrm{e}}=595, p<.001\right.$; $\left.F_{2}(1,76)=7.50, M S_{\mathrm{e}}=1,421, p<.01\right]$, and RTs were faster in Block 2 than in Block $1\left[F_{1}(1,39)=32.70, M S_{\mathrm{e}}=\right.$ $\left.304, p<.001 ; F_{2}(1,76)=130.27, M S_{\mathrm{e}}=255, p<.001\right]$.

Consistent with Paap and Noel's (1991) findings, word frequency and regularity interacted $\left[F_{1}(1,39)=30.08\right.$, $M S_{\mathrm{e}}=224, p<.001 ; F_{2}(1,76)=7.09, M S_{\mathrm{e}}=1,421, p<$ $.01]$. There was a large difference in RTs between regular and exception words when the words were low in frequency, but little difference when the words were high in frequency. Word frequency and block also interacted $\left[F_{1}(1,39)=10.86, M S_{\mathrm{e}}=177, p<.005 ; F_{2}(1,76)=\right.$ $\left.18.30, M S_{\mathrm{e}}=255, p<.001\right]$; there was a larger effect of repetition for low-frequency words than for highfrequency words. The two-way interaction between regularity and block was significant $\left[F_{1}(1,39)=56.1, M S_{\mathrm{e}}=\right.$ $\left.198, p<.001 ; F_{2}(1,76)=9.6, M S_{\mathrm{e}}=255, p<.005\right]$; the regularity effect was larger in Block 1 than in Block 2. Finally, there was a significant three-way interaction between word frequency, regularity, and block $\left[F_{1}(1,39)=\right.$ $5.77, M S_{\mathrm{e}}=223, p<.05 ; F_{2}(1,76)=5.39, M S_{\mathrm{e}}=255, p<$

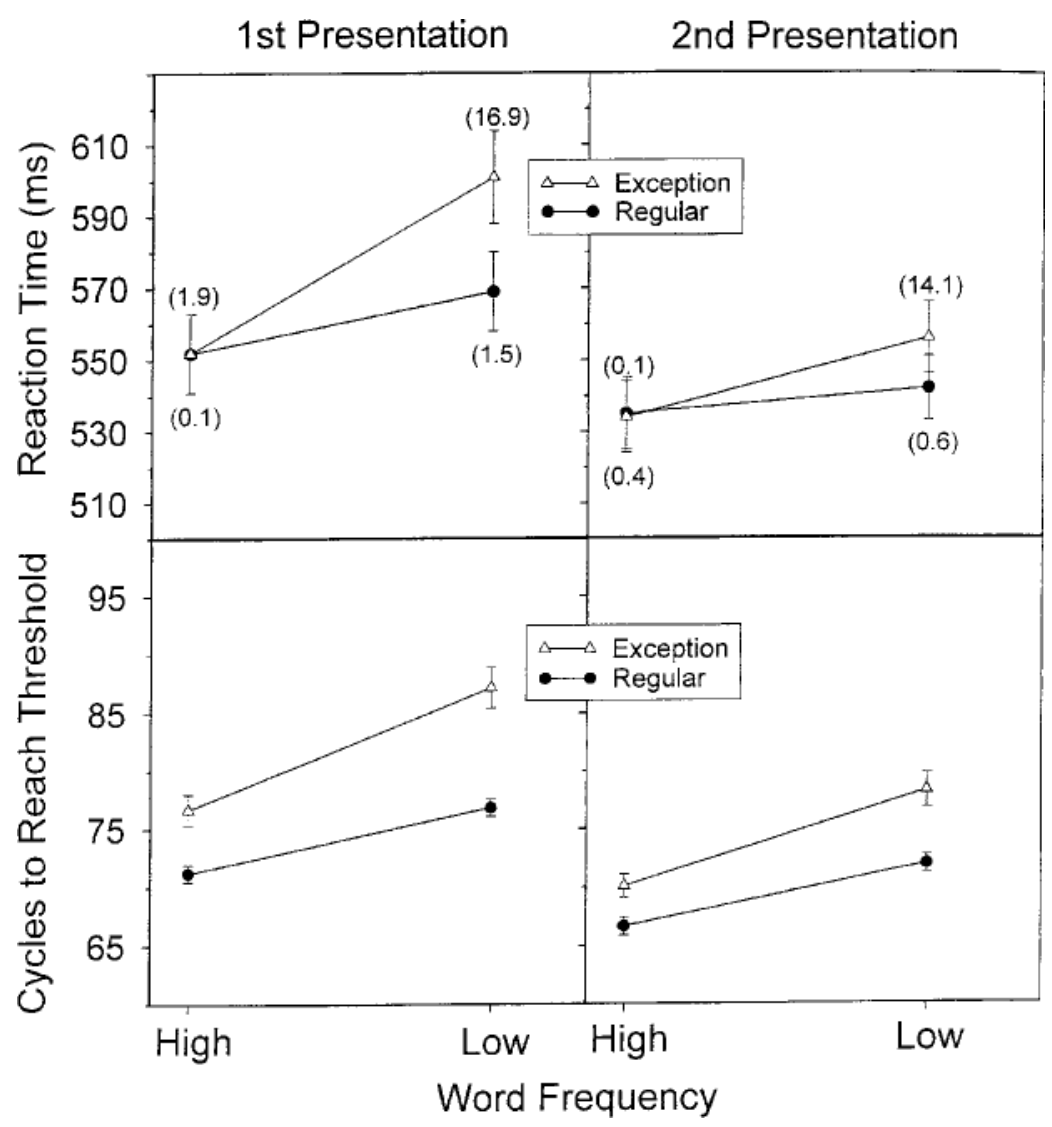

Figure 2. Top panels: Mean reaction times (in milliseconds), associated standard errors $( \pm 1 S E M)$, and percentage of error (in parentheses) as a function of word frequency, regularity, and repetition. Bottom panels: Cycles to reach phoneme threshold in DRC as a function of word frequency, regularity, and repetition. 
$.05]$, in which the two-way interaction between regularity and frequency in Block 1 was reduced in Block 2.

Error data. The error data can be seen in Figure 2. In the absence of any evidence that the pattern of errors undermined the results of the RT analysis in any way (i.e., no obvious speed-error tradeoff), no formal analysis of the error data was conducted.

\section{Discussion}

The results of this experiment replicate two previous observations. First, the standard two-way interaction is observed, in which the exception effect is larger for lowfrequency words than for higher frequency words (e.g., Paap \& Noel, 1991; Seidenberg, 1985; Waters \& Seidenberg, 1985). Second, repetition speeds naming time (e.g., Monsell, 1991; Rastle \& Coltheart, 1999a; Scarborough et al., 1977). For present purposes, however, the most important point is that the predicted three-way interaction between word frequency, regularity, and repetition was significant. This consisted of a smaller twoway interaction between word frequency and regularity in Block 2, as compared with Block 1. These findings are consistent with a speed-of-processing account in which repetition speeds up the operation of the addressed routine, relative to the operation of the assembled routine. The consequence is that the assembled routine has less opportunity to provide an output that conflicts with the output of the addressed routine, and hence a reduced exception effect for low-frequency words is observed.

Three other points relevant to our results and interpretation merit discussion. The first point concerns the possible influence of episodic memory on naming. In the present work, we have assumed that episodic traces associated with the first presentation of a word play little or no role in subsequent naming. This assumption is consistent with Monsell (1991; see also Monsell \& Hirsh, 1998), who suggested that episodic memory plays a minimal role in repetition priming and then "only in the case of a task dependent on a familiarity criterion, such as lexical decision" (p. 187). In addition, Monsell points out that although a few studies have found an influence of episodic memory on repetition priming, the great majority have found robust repetition priming in the absence of episodic memory. This implies that even when present, episodic memory does not exert a large influence on performance.

A second point concerns the potential influence of age of acquisition. Morrison and Ellis (1995) claimed that word frequency has no effect in naming but that age of acquisition (which is highly correlated with word frequency) does. More recent evidence provided by Gerhand and Barry (1998) suggests that Morrison and Ellis's failure to observe a word frequency effect in naming is a Type 2 error. However, given that both sets of investigators observed an age-of-acquisition effect in naming, does the "word frequency" effect observed here reflect age of acquisition, word frequency, or both factors? The present experiment was not designed to determine which of these two factors is responsible for the effect reported here, but it should be noted that the age-of-acquisition account makes no provisions for any effect of exposure to a word after it has been learned. Logically, then, the interaction of word frequency and repetition reported here does not reflect an age-of-acquisition effect (although age of acquisition might account for some of the main effect of word frequency).

Another issue concerns the broader question of what RT experiments can actually tell us about underlying mental processes. It might be argued that experiments such as the present one tell us little about such processes, because the effect of a manipulated factor is always expected to be largest in the slowest condition. The counterargument is that, on this account, it should not be possible to find additive effects of two or more factors on RT, yet there are a large number of experiments in which two main effects are substantial but there is no evidence of a two-way interaction (Sternberg, 1998). A second-order argument is to grant the counterargument, but suppose that repetition is a special case of a factor that interacts with all other factors. This argument is also problematic, given that Scarborough et al. (1977) reported that repetition and bias (proportion of words to nonwords) have additive effects on RT in the context of a lexical decision experiment that also produced an interaction between repetition and word frequency.

\section{SIMULATION}

Rastle and Coltheart (1999a) reported a series of repetition experiments in the context of a naming task. For present purposes, the most interesting aspect of that work is that their implemented DRC model could simulate the priming effect from previously presented, phonologically identical items (pseudohomophones) on the naming of word targets. This was accomplished by instituting a decay parameter in the model that allowed residual activation from previous items (i.e., primes) to influence activation patterns created by new items (i.e., targets; see Rastle \& Coltheart, 1999a, for details and for simulation examples). An obvious question is whether DRC can simulate the three-way interaction reported here. A simulation with the stimuli used here was therefore conducted. Each word was presented to the model and then presented to the model again following an interstimulus interval of 40 cycles, during which no intervening items were presented. It should be noted that no attempt was made here to evaluate the time course of the effect of repetition in the model; that is left to future work. Furthermore, the simulation differed from the present experiment in that there are no intervening items between repetitions. This issue will also need to be addressed in future work. The purpose of the present simulation was simply to inquire whether, using the same decay parameter as that reported in Rastle and Coltheart (1999a), DRC could produce the pattern observed in the human data.

The simulation was successful in that it reproduced the three-way interaction observed in the human data. 
More specifically, the regularity effect was larger for low-frequency words than for high-frequency words, repetition facilitated low-frequency words more than it did high-frequency words, and repetition reduced the size of the regularity $\times$ frequency interaction. These data can be seen in the bottom panel of Figure 1. More formally, the three-way interaction between word frequency, regularity, and repetition was significant $[F(1,65)=$ $\left.14.615, M S_{\mathrm{e}}=0.576, p<.001\right]$.

\section{ALTERNATIVE ACCOUNTS}

There are, of course, other implemented frameworks that have been advanced to account for naming performance and, more specifically, the regularity $\times$ frequency interaction (e.g., Plaut et al., 1996; Zorzi, Houghton, \& Butterworth, 1998). Both of these accounts are dualroute. In the former case, there is an implemented orthography-phonology pathway and an orthographysemantics-phonology pathway that has not been implemented. In the latter case, there are two nonsemantic routes (a sublexical route and a lexical route). However, although dual-route, both of these models differ from DRC in the sense that they involve distributed representations at some level, rather than purely localist ones throughout.

The difficulty with both the Plaut et al. (1996) and the Zorzi et al. (1998) models in the present context ${ }^{3}$ is that, currently, there is nothing implemented that produces a repetition effect. As it stands, the training period of the models ends when errors reach a criterion level. Additional exposure to words has no effect on naming performance. It is not sufficient to simply allow these models to continue to learn with each additional word presentation, because learning depends on explicit feedback from a "teacher" (back-propagation) — a situation that does not occur in the present experiment. In addition, the present results suggest the further constraint that any influence of repetition must selectively affect the efficiency of lexical-semantic pathways while leaving translation from orthography to phonology unaffected (or at least, affect the lexical-semantic pathways more than the sublexical one, in the Zorzi et al. model, and more than the orthography-phonology pathway, in the Plaut et al. model). Given these considerations, it may be that these models need additional mechanisms to produce repetition effects. For example, a set of fast weights that decay over time could be added to the lexical-semantic pathway. Details aside, it seems hard to imagine that such a change would not produce a main effect of repetition. The critical question, of course, is whether these models would produce the three-way interaction reported here. It seems impossible to answer this question without a simulation.

There are, of course, yet other accounts of the role of orthography and phonology in visual word recognition (e.g., Berent \& Perfetti, 1995, Frost, 1998, and Van Orden et al., 1990, among others). The difficulty is that (1) they are not implemented in any form of simulation and (2) they are so underspecified that it is difficult to determine whether they would predict the three-way interaction observed here (or produce such an interaction if implemented versions of these accounts existed). That said, we want to be quite clear: It is not being claimed that other frameworks cannot simulate the three-way interaction observed here; rather, we await such a demonstration.

\section{CONCLUSION}

The present results are consistent with a localist dualroute account of visual word recognition (e.g., Besner, 1999; Coltheart et al., 1993; Paap \& Noel, 1991; Rastle \& Coltheart, 1999a, 1999b), as well as with an implemented version of such a dual-route model with localist representations (Coltheart et al., 2001; Rastle \& Coltheart, 1998, 1999a, 1999b). It remains to be seen whether these results can be simulated by a different class of connectionist models, such as those advanced by Plaut et al. (1996) and Zorzi et al. (1998).

More generally, given the framework advocated here, the reduction in the magnitude of the regularity effect across blocks is consistent with the conclusion that, for skilled readers, continued experience with known words serves to increase the extent to which orthographic wholeword knowledge dominates the process of generating a pronunciation.

\section{REFERENCES}

BALUCH, B., \& BESNER, D. (1991). Visual word recognition: Evidence for strategic control of lexical and nonlexical routines in oral reading. Journal of Experimental Psychology: Learning, Memory, \& Cognition, 17, 644-652.

Berent, I., \& Perfetti, C. A. (1995). Roses are reezes: The two cycle model of phonological assembly in English. Psychological Review, 102, 146-184.

BESNER, D. (1999). Basic processes in reading: Multiple routines in localist and connectionist models. In R. Klein \& P. McMullen (Eds.), Converging methods for understanding reading and dyslexia (pp. 413458). Cambridge, MA: MIT Press.

Coltheart, M., Curtis, B., Atkins, P., \& Haller, M. (1993). Models of reading aloud: Dual-route and parallel-distributed processing approaches. Psychological Review, 100, 589-608.

Coltheart, M., Patterson, K. E., \& Marshall, J. C. (1980). Deep dyslexia. London: Routledge \& Kegan Paul.

Coltheart, M., \& RAst Le, K. (1994). Serial processing in reading aloud: Evidence for dual route models of reading. Journal of Experimental Psychology: Human Perception \& Performance, 20, 1197-1211.

Coltheart, M., Rastle, K., Perry, C., Langdon, R., \& Ziegler, J. (2001). DRC: A dual route cascaded model of visual word recognition and naming. Psychological Review, 108, 204-256.

Forster, K. I., \& Chambers, S. M. (1973). Lexical access and naming time. Journal of Verbal Learning \& Verbal Behavior, 12, 627-635.

Frederiksen, J. R. \& Kroll, J. F. (1976). Spelling and sound: Approaches to the internal lexicon. Journal of Experimental Psychology: Human Perception \& Performance, 2, 361-379.

Frost, R. (1998). Toward a strong phonological theory of visual word recognition: True issues and false trails. Psychological Bulletin, 123, 71-99.

Gerhand, S., \& BARry, C. (1998). Word frequency effects in oral reading are not merely age-of-acquisition effects in disguise. Journal of Experimental Psychology: Learning, Memory, \& Cognition, 24, 267-283. 
GraINGER, J., \& JACOBS, A. (1996). Orthographic processing in visual word recognition: A multiple read-out model. Psychological Review, 103, 518-565.

Hung, D. L., \& Tzeng, O. J. L. (1981). Orthographic variations and visual information processing. Psychological Bulletin, 90, 377-414.

JARED, D. (1995, November). Spelling-sound consistency affects the naming of high-frequency words. Poster session presented at the 36th Annual Meeting of the Psychonomic Society, Los Angeles.

MCCANN, R. S., \& BESNER, D. (1987). Reading pseudohomophones: Implications for models of pronunciation and the locus of word frequency effects in word naming. Journal of Experimental Psychology: Human Perception \& Performance, 13, 14-24.

McClelland, J. L., \& Rumelhart, D. E. (1981). An interactive activation account of context effects in letter perception: Part 1. An account of basic findings. Psychological Review, 88, 375-407.

Monsell, S. (1991). The nature and locus of word frequency effects in reading. In D. Besner \& G. W. Humphreys (Eds.), Basic processes in reading: Visual word recognition (pp. 148-197). Hillsdale, NJ: Erlbaum.

Monsell, S., \& HirSh, K. W. (1998). Competitor priming in spoken word recognition. Journal of Experimental Psychology: Learning, Memory, \& Cognition, 24, 1495-1520.

Morrison, C. M., \& Ellis, A. W. (1995). Roles of word frequency and age of acquisition in word naming and lexical decision. Journal of Experimental Psychology: Learning, Memory, \& Cognition, 21, 116-133.

PAAP, K. R., \& Noel, R. W. (1991). Dual-route models of print to sound: Still a good horse race. Psychological Research, 53, 13-24.

Patterson, K. E., \& Coltheart, V. (1987). Phonological processing in reading: A tutorial review. In M. Coltheart (Ed.), Attention and performance XII: The psychology of reading (pp. 421-447). Hillsdale, NJ: Erlbaum.

Patterson, K. E., Marshall, J. C., \& Coltheart, M. (1985). Surface dyslexia. Hillsdale, NJ: Erlbaum.

Plaut, D. C., McClelland, J. L., Seidenberg, M. S., \& Patterson, K. E. (1996). Understanding normal and impaired word reading: Computational principles in quasi-regular domains. Psychological Review, 103, 56-115.

Pugh, K. R., Shaywitz, B. A., Shaywitz, S. E., Constable, R. T., Skudlarski, P., Fulbright, R. K., Bronen, R. A., Shankweiler, D. P., Katz, L., Fletcher, J. M., \& Gore, J. C. (1996). Cerebral organization of component processes in reading. Brain, 119, 1221-1238.

Rastle, K., \& Coltheart, M. (1998). Whammies and double whammies: The effect of length on nonword reading. Psychonomic Bulletin \& Review, 5, 277-282.

Rastle, K., \& Coltheart, M. (1999a). Lexical and nonlexical phonological priming in reading aloud. Journal of Experimental Psychology: Human Perception \& Performance, 25, 461-481.

Rastle, K., \& Coltheart, M. (1999b). Serial and strategic effects in reading aloud. Journal of Experimental Psychology: Human Perception \& Performance, 25, 482-503.

Roberts, M., Rastle, K., Coltheart, M., \& Besner, D. (2000, July). When parallel processing in visual word recognition is not enough: New evidence from naming. Poster presented to the joint meeting of the Experimental Psychology Society and the Canadian Society for Brain, Behavior, and Cognitive Science, Cambridge.

Scarborough, D., Cortese, C., \& Scarborough, H. (1977). Frequency and repetition effects in lexical memory. Journal of Experimental Psychology: Human Perception \& Performance, 3, 1-17.
SeIDENBERG, M. S. (1985). The time course of phonological code activation in two writing systems. Cognition, 19, 1-10.

Seidenberg, M. S., Waters, G. S., Barnes, M. A., \& Tanenhaus, M. K. (1984). When does irregular spelling or pronunciation influence word recognition? Journal of Verbal Learning \& Verbal Behavior, 23, 383-404.

Sternberg, S. (1998). Discovering mental processing stages: The method of additive factors. In D. Scarborough \& S. Sternberg (Eds.), An invitation to cognitive science: Vol. 4. Methods, models, and conceptual issues (pp. 703-863). Cambridge, MA: MIT Press.

Treiman, R., Mullennix, J., Bijeljac-Babic, R., \& RichmondWelty, E. (1995). The special role of rimes in the description, use, and acquisition of English orthography. Journal of Experimental Psychology: General, 124, 107-136.

Van Orden, G. C., Pennington, B. F., \& Stone, G. O. (1990). Word identification in reading and the promise of subsymbolic psycholinguistics. Psychological Review, 97, 488-522.

VAn Selst, M., \& Jolicceur, P. (1994). A solution to the effect of sample size on outlier estimation. Quarterly Journal of Experimental Psychology, 47A, 631-650.

Waters, G. S., \& Seidenberg, M. S. (1985). Spelling-sound effects in reading: Time-course and decision criteria. Memory \& Cognition, 13, 557-572.

WeEkes, B. (1997). Differential effects of number of letters on word and nonword naming latency. Quarterly Journal of Experimental Psychology, 50A, 439-456.

ZorZI, M. (2000). Serial processing in reading aloud: No challenge for a parallel model. Journal of Experimental Psychology: Human Perception \& Performance, 26, 847-856.

Zorzi, M., Houghton, G., \& Butterworth, B. (1998). Two routes or one in reading aloud? A connectionist dual process model. Journal of Experimental Psychology: Human Perception \& Performance, 24, 1131-1161.

\section{NOTES}

1. An exception word can contain segments that are not atypical in terms of their spelling-sound correspondences. For example, the only segment in have that is exceptional is $a$, because it is not pronounced like the $a$ in gave, save, and rave.

2. Consistent with this account, Seidenberg (1985) reported that faster readers (presumably, more skilled) showed a smaller exception effect than did slower readers. Unfortunately, Seidenberg did not provide the associated error rates for each condition. This leaves open the possibility that the faster readers merely traded speed for errors, as compared with the slower readers.

3 . Both of these models have a number of other difficulties; for example, neither model seems likely to be able to accommodates a letter length effect in naming time to nonwords, but not to words after the effect of neighborhood size is partialled out (see Besner, 1999, for a discussion). The former model also fails to simulate the regularity $\times$ serial position interaction reported by Rastle and Coltheart (1999b). The latter model does simulate the regularity $\times$ serial position interaction, but only when consistency is confounded with regularity (see Zorzi, 2000). More recent work shows that another set of items produces a regularity $X$ serial position interaction in the human data and in DRC, but not in Zorzi et al.'s model (Roberts, Rastle, Coltheart, \& Besner, 2000). 
APPENDIX

Stimulus Set

\begin{tabular}{|c|c|c|c|}
\hline \multicolumn{2}{|c|}{ Low Frequency } & \multicolumn{2}{|c|}{ High Frequency } \\
\hline Exception & Regular & Exception & Regular \\
\hline buryc & buds & been $^{\mathrm{a}}$ & best \\
\hline caste & canes & both & book $^{b}$ \\
\hline comb & coil & come & came \\
\hline crow & curl & done & dark \\
\hline glove & grade & door ${ }^{a}$ & deep \\
\hline lurec & lump & foot & flat \\
\hline lute $\mathrm{a}^{\mathrm{a}}$ & lode & give & game \\
\hline poura & pops & good & gain \\
\hline ruse & rump & have & high \\
\hline sew & sock & most & more \\
\hline $\operatorname{sans}^{\mathrm{d}}$ & sage & move & miss \\
\hline sues & suck & said & same \\
\hline sown & sobs & says $^{a}$ & seem \\
\hline wand & wade & sure & soon \\
\hline warn & weed & touch & train \\
\hline warp & wick & want & wall ${ }^{b}$ \\
\hline wasp & weld & warm & wage \\
\hline wily $^{\mathrm{c}}$ & wilt & were & well \\
\hline wool & woke & word & west \\
\hline worm & wink & work & week \\
\hline
\end{tabular}

a This word is regular for the dual-route cascaded(DRC) model (i.e., it obeys the model's GPC rules), so it was omitted from the simulation. The model's GPC rules are based on Australian English; hence, been is regular. b This word is irregular for the DRC model (i.e., it disobeys the model's GPC rules), so it was omitted from the simulation. ${ }^{\mathrm{c}}$ This word is disyllabic, so it is not in the DRC vocabulary and was therefore omitted from the simulation. $\mathrm{d}$ This word is not in the DRC vocabulary and was therefore omitted from the simulation.

(Manuscript received May 4, 1998;

revision accepted for publication September 7, 2000.) 